\title{
BERGSON LEITOR DE LUCRÉCIO: AS IMPLICAÇÕES EXISTENCIAIS DO DETERMINISMO
}

\author{
Jonas Gonçalves COELHO ${ }^{1}$ \\ n RESUMO: Tomamos como objeto de análise a obra precoce de Bergson, os \\ Extraits de Lucrèce, procurando mostrar que ao privilegiar as implicações \\ existenciais negativas do determinismo, prefigura e justifica o fato de dedicar \\ grande parte de seu pensamento filosófico posterior à crítica ao determinismo \\ e à defesa da liberdade. \\ n PALAVRAS-CHAVE: Bergson; Lucrécio; determinismo; existencial.
}

Em 1883, cinco anos antes do aparecimento da primeira grande obra filosófica de Bergson, o Essai sur les données immédiates de la conscience, publicou-se, pela primeira vez, o texto de sua autoria, intitulado Extraits de Lucrèce (Bergson, 1972), acrescido de comentários, notas e estudos. O que chama a atenção nessa obra é o fato de aí já estarem prefiguradas duas das grandes temáticas filosóficas que ocuparão posteriormente o pensamento de Bergson. Em primeiro lugar, os Extraits de Lucrèce fornecem o modelo do tratamento que deve ser dado pelo filósofo à História da Filosofia, ou seja, o modo pelo qual se deve abordar e o que se deve buscar em uma obra filosófica. Em segundo lugar, esse texto pre-

\footnotetext{
1 Departamento de Ciências Humanas - Faculdade de Arquitetura, Artes e Comunicação/Unesp 17033-360 - Bauru - SP/Brasil
} 
nuncia uma temática que atravessa a obra de Bergson: a crítica ao determinismo.

Como veremos, diferentemente de suas obras posteriores, nas quais ataca as várias formas de determinismo, a partir de seus fundamentos, ressaltando sua falta de consistência, nesse texto precoce sobre Lucrécio, encontramos a motivação para esse persistente ataque: as implicações existenciais negativas do determinismo.

Bergson começa seu estudo ${ }^{2}$ pelas dificuldades de se publicar uma obra com trechos escolhidos de Lucrécio, considerando que há um grande risco de induzir o leitor a uma idéia falsa a respeito de seu pensamento. Propõe então um modelo de abordagem filosófica a ser seguido: quando se estuda um autor, o "essencial é compreendê-lo bem" (Bergson, 1972, p.266), e para a boa compreensão de uma obra filosófica, fazse necessária a identificação do "grande princípio filosófico" que a norteia. O objetivo de Bergson, portanto, não é criticar as idéias de Lucrécio, mas encontrar esse "grande princípio" na obra La nature, buscar o que está por trás das descrições, dos quadros que Lucrécio pinta a respeito da vida humana.

O ponto de partida de Bergson, aquilo que mais o impressiona na obra do poeta, é o sentimento que ela claramente expressa: a "melancolia profunda". Há tristeza e desânimo na descrição dramática que Lucrécio faz da vida humana em geral, caracterizada como monótona, rotineira, inútil, insatisfeita, amarga, triste. Para Bergson, esse sentimento é tão dominante, tão amplamente sugerido e justificado, que mesmo as exceções e, de certa forma, a própria solução apontadas pelo poeta - o conformismo -, não conseguem disfarçá-lo.

O poema da Natureza é triste e desanimador. Para que viver? A vida é monótona; é um movimento sobre o mesmo lugar, um desejo sempre insatisfeito. Os prazeres são enganosos, nenhuma alegria é pura, e da fonte mesma das volúpias se eleva uma espécie de amargura que nos sufoca no

\footnotetext{
2 Restringimos nossa exposição apenas à primeira parte do texto de Bergson sobre Lucrécio, a qua "compreende um estudo sobre a poesia, a filosofia e a física" e onde o filósofo procura destacar "a originalidade das idéias do poeta, muito freqüentemente confundidas com as de Epicuro ou as de Demócrito" (Bergson, 1972, p.266).
} 
meio de perfumes e de flores. Veja também como a criança chora em seu nascimento; ela enche o ar com os seus gritos lúgubres, e é justo: lhe restam tantos males a atravessar na vida! Mais tarde, homem feito, ele trabalhará, se afligirá, se elevará pelos esforços sobre humanos à fortuna e às honras; trabalho perdido! Ele viveria mais feliz e mais tranqüilo nos campos, sua alma estaria menos inquieta, e ele estaria mais perto da natureza. A felicidade está refugiada no campo? Aí é pelo menos feliz aquele que sem medo e sem preocupação cultiva pacificamente sua terra? O poeta, após nos ter feito esperar um instante, nos arrebata esta última ilusão. Pobre de mim! se a fortuna é pérfida, a terra é avarenta. O lavrador usa o ferro, como as suas forças, e a gleba não lhe dá nem mesmo o necessário. $\mathrm{O}$ vinhateiro plantou a sua vinha, mas o sol a seca. Os dois suspiram e balançam a cabeça tristemente. E eles não vêem que a terra está cansada de produzir, que tudo neste mundo envelhece, se fatiga, se decomporá um dia. É assim que nós passamos a melhor parte de nossas vidas a perseguir honras inúteis, ou a cultivar uma terra que resiste a nosso labor e se cansa de produzir. Depois a velhice chega, e com ela, o medo pueril da morte. $O$ velho se a representa e se aflige. Quanto mais esperança, tanto mais alegria! sua família não acorrerá mais ao seu encontro, sua mulher e seus filhos não virão mais disputar seus beijos! e ele não vê que a morte é o fim de tudo, que se ela nos priva das doçuras da vida, ela nos livra também da necessidade que nela podemos ter, e das penas que as acompanham sempre. Assim tudo é miséria neste mundo, e nossa maior consolação é pensar que tudo terminará para nós com a vida. É a convicção do sábio, é a conclusão de toda filosofia. O papel da ciência é nos mostrar, com efeito, que nós mal contamos no universo, onde os deuses não se ocupam absolutamente de nós, onde nós somos o que uma combinação fortuita de elementos nos têm feito, onde nós nos decomporemos como se decompõem os outros corpos. E o sábio, que conhece esta grande verdade e que nela penetra, espera tranqüilamente uma morte na qual sabe bem que se aniquilará inteiramente: ele possui assim a ciência suprema, ao mesmo tempo que experimenta as mais doces alegrias que o homem pode atingir (p.269).

A Bergson interessa a "causa primeira da melancolia de Lucrécio", a "idéia diretriz do poema" (p. 270), a chave para a compreensão da obra e até mesmo da alma do poeta: “isso será já penetrar muito longe na alma do poeta” (p. 270). Começa por afastar os fatos e as explicações sugeridas pelo próprio Lucrécio. Não devemos privilegiar fatos como "o espetáculo das guerras civis" e as lutas sangrentas presenciadas por Lucrécio, embora, certamente, sejam fatos relevantes que deixaram "sombrias imagens" em sua alma, marcas que também podem ser encontradas em sua obra. Não devemos também nos enganar pela argumentação do próprio poeta segundo a qual o grande problema não são as guerras, as dis- 
córdias, os desastres públicos, a violência, os sofrimentos, a ambição e as intrigas a ela associados, mas o desvio que eles produzem em relação à filosofia, à ciência, como se fossem males apenas por arrancarem "a inteligência a estas nobres preocupações, as únicas dignas dela” (p. 271). Bergson considera que essa não é a "linguagem de um homem que sofre profundamente os males de sua pátria, e que chora sobre a ruína pública" (p. 272), como é o caso de Lucrécio.

Para Bergson a verdadeira razão, "a idéia mestra do poema" $L a$ nature, a causa profunda da melancolia de Lucrécio, é o determinismo que o poeta desvenda na natureza que tanto ama. Lucrécio está muito menos interessado em explicar o modo como a natureza funciona do que em "mostrar a que ponto cada um de seus atos [do homem] era determinado e fatal" (p. 273). Embora esse determinismo não esteja formulado explicitamente em nenhum lugar do texto de Lucrécio, todo ele pode ser considerado como seu desenvolvimento, que Bergson assim resume:

sob esta natureza pitoresca e graciosa, por detrás desses fenômenos infinitamente diversos e sempre mutáveis, leis fixas e imutáveis trabalham uniformemente, invariavelmente, e produzem, cada uma por sua parte, efeitos determinados. Não há acaso, nenhum lugar para o capricho; por toda parte forças que se reúnem ou se compensam, causas e efeitos que se encadeiam mecanicamente. Um número indefinido de elementos, sempre os mesmos, existe por toda a eternidade; as leis da natureza, leis fatais, fazem com que os elementos se combinem e se separem; e estas combinações, estas separações são rigorosamente e de uma vez por todas determinadas. Nós percebemos os fenômenos de fora, no que eles têm de pitoresco; cremos que eles se sucedem e se substituem à medida de sua fantasia; mas a reflexão, a ciência nos mostram que cada um deles podia ser matematicamente previsto, porque ele é a conseqüência fatal do que havia antes dele (...) A natureza está empenhada, de uma vez por todas, a aplicar invariavelmente as mesmas leis; ela está nela empenhada por uma espécie de contrato, foedus, e este contrato é eterno (...) Resulta daí que cada causa não produz senão um efeito determinado (...) que os mesmos seres nascem e se desenvolvem sempre nas mesmas condições (...) que as mesmas raças, as mesmas espécies se conservam (...) É porque a natureza tem assim contraído compromissos que cada um dos fenômenos pode ser previsto matematicamente, que cada um deles é determinado (...) (p.272).

Bergson não tem dúvida de que essa concepção determinista, presente sob aspectos diversos em cada página da obra de Lucrécio, essa idéia "que obsedia o poeta", é a que o entristece e produz a sua melanco- 
lia, fazendo com que se apiede da espécie humana, da sua impotência, insignificância e ignorância diante das leis naturais.

Que pode ela [a espécie humana] no meio dessas forças cegas que trabalham e trabalharão em torno dela, a despeito dela, sempre as mesmas durante a eternidade dos tempos? Conta ela para alguma coisa neste universo sem limites onde nasceu por acidente, pobre combinação de átomos que a fatalidade das leis naturais reuniu por algum tempo, e que as mesmas forças dispersarão um dia? Nós cremos que a matéria é feita para nós, como se nós não estivéssemos submetidos às mesmas leis que ela. Cremos que os deuses amigos ou ciumentos nos protegem ou nos perseguem, como se forças estranhas, caprichosas pudessem intervir na natureza, como se as leis implacáveis da matéria não nos conduzissem na mesma corrente que conduz as coisas (...) Aquele que geme sobre sua sorte não conhece absolutamente a verdadeira natureza das coisas; ele imagina que lutou, e chora, como um vencido sobre a sua derrota. Se refletisse, se soubesse, se se elevasse até as "regiões serenas" da filosofia, compreenderia que todo lamento é inútil e mesmo sem propósito, porque a natureza segue invariavelmente seu curso sem se preocupar conosco (p.274).

Nem mesmo o argumento de Lucrécio, segundo o qual o determinismo é uma fonte das "mais doces consolações" para a humanidade, pois não apenas nos inocenta de nosso fracasso mas também fornece uma resignação que por si pode ser geradora de satisfação, impressiona Bergson que o considera apenas como uma ironia. É nesse sentido que se refere aos consolos de Lucrécio aos agricultores e aos velhos como "consolações estranhas (...) que deveriam, parece, em um primeiro momento, agravar os tormentos do pobre homem" (p.274). Afinal, não se pode compreender como o conhecimento dessa impotência da natureza humana poderia produzir consolo. E é justamente esta "concepção original da natureza humana" que o poeta está propondo:

O agricultor suspira e balança a cabeça; e ele não vê que o universo marcha pouco a pouco para a sua ruína! É que na idéia de Lucrécio, só se queixa quem pode crer um instante na resistência possível (...) A velhice, por uma lei eterna, deve ceder lugar à juventude; os seres se reproduzem necessariamente às custas de outros seres. Se o velho se desse conta dessa lei invariável e universal, ele se resignaria naturalmente. Quando a quantidade de matéria que se perde não é mais igual àquela que os alimentos trazem, é preciso que o corpo pereça, é a justiça (...) (p.274).

Para justificar essa interpretação que privilegia o papel desempenhado pelo determinismo na obra La nature, trazendo, assim, à luz, a 
"idéia essencial do poema" de Lucrécio e, desse modo, exaltar a grandeza, a "originalidade do poeta", Bergson o compara com os filósofos gregos que o teriam influenciado: Demócrito e Epicuro.

Bergson considera o pensamento de Demócrito como a expressão mais perfeita do materialismo e a teoria atomista por ele defendida, "um dos mais profundos sistemas de filosofia que a antigüidade produziu" (p.276). Demócrito, para quem as explicações mais simples são as melhores, postula que a imensa variedade dos fenômenos do universo é o resultado da combinação infinita de um número também infinito de elementos muito simples, mais ou menos idênticos, os átomos. Esses são definidos como "corpos excessivamente tênues, tão sutis que não se pode percebê-los, tão pequenos que não se pode dividi-los" (p.276). Sendo imperceptíveis, indivisíveis, eternos, indestrutíveis, sem cor, sem sabor, sem peso e sem resistência não estão sujeitos à mudança. A forma é a sua única qualidade. É por ela que eles se diferenciam uns dos outros, e, reunidos em número suficiente, formam corpos que podem ser vistos e tocados. Através do movimento dos átomos no vazio infinito, de seu choque e aglomeração, foram formando-se, sucessivamente, a terra , a lua, o sol , os astros, os seres vivos. Desse modo, Demócrito explica, a partir do movimento dos átomos, tanto os fenômenos da natureza, quanto a alma e até os "atos de pensamento".

A alma, com efeito, que parece animar os corpos organizados, é, ela também, um composto de átomos, mas de átomos muito móveis, redondos e polidos. Os pensamentos que se sucedem em nossa alma são apenas movimentos de átomos que a compõem. Se ela percebe os objetos materiais, os compostos de átomos que a cercam, é porque esses objetos emitem, a todo momento e por todos os lados, imagens extremamente pequenas que vêm tocar os órgãos dos sentidos (p.278).

Para Bergson, essa concepção de Demócrito exerceu grande influência sobre o pensamento de Epicuro. Este privilegiava o viver feliz, acreditando que o objeto exclusivo da filosofia é tornar mais curto o caminho para a felicidade, entendida como paz interior e serenidade de espírito: "Saber gozar o presente, se colocar ao abrigo da inquietude e do medo, eis a verdadeira sabedoria e o fim último de toda filosofia" 
(p.279). Mas Epicuro também acreditava que essa felicidade é perturbada, quando se teme a interferência dos deuses bons ou maus em nossa vida, quando se acredita que eles estão por toda parte, vigiandonos, e, enfim, pelo medo da morte, mais precisamente dos suplícios do inferno. Essa "dupla superstição" seria a "fonte de inesgotáveis inquietudes e crimes, envenenando a vida, corrompendo a felicidade e a moralidade" (p.279). Desse modo, só haveria felicidade se os deuses não existissem e a morte fosse o fim de tudo. Bergson encontra aí o motivo pelo qual Epicuro adota o atomismo de Demócrito: este serviria muito bem aos seus propósitos.

Epicuro introduz modificações na concepção atomista: o peso aparece como a qualidade dos átomos que é responsável por seu movimento eterno, paralelo, vertical e com velocidades iguais. O desvio, mesmo que leve, dos átomos em seu percurso, fruto do capricho, provocaria o choque entre muitos deles, dando origem a um movimento rotatório ou turbilhonar e à sua aglomeração. Formar-se-ia, assim, um mundo, e a partir de outros processos semelhantes, constituir-se-iam, incessantemente, novos mundos. Esses movimentos dos átomos e a eterna combinação fortuita deles produziriam infinitas combinações. Não precisamos, assim, postular a existência de uma causa inteligente para explicar os efeitos ordenados que nos surpreendem.

As combinações maravilhosas que admiramos hoje e que chamamos seres vivos deviam, pois, fatalmente produzir-se desde que se espere um tempo tão longo: elas se produziram; e como as outras desapareceram, incapazes que eram de viver e de se conservar, nós não percebemos senão as melhores, as combinações perfeitas, e admiramos a ordem, a pretensa inteligência da natureza. $O$ acaso somente as tem engendrado, como tem engendrado milhares de outras (p.282).

Esse mesmo processo casual responsável pelo surgimento do mundo, da vida e do homem, produziria, inevitavelmente, a destruição de todos eles, a formação de novos mundos, e assim eternamente: "o movimento perpétuo dos átomos fará que em um dia ou outro tudo se dissolverá, tudo se decomporá; os átomos, tornados poeira, se reaproximarão ainda; combinações novas darão mundos novos; e assim sucessivamente, durante toda a eternidade do tempo" (p.282). Sendo a alma humana composta por átomos, ela também desaparecerá, seus átomos desagregar-se-ão com a decomposição do corpo. Mas, como já dissemos, isso não é para Epicuro um mal, visto que não teríamos mais motivos para temer nem o inferno, nem os deuses, os quais, mesmo que se admita 
a sua existência, "são incapazes de intervir no universo, visto que tudo se explica sem eles" (p.283).

\section{4}

O elogio a Epicuro está presente em toda a obra de Lucrécio que tem por ele "uma admiração profunda", considerando-o "não somente um sábio, mas o sábio por excelência (...) o grande benfeitor da humanidade (...) ele o ama de toda a sua alma, ele o adora como um deus" (p.283). Embora haja semelhanças entre os dois pensadores, o que interessa a Bergson é a originalidade, a diferença que, a seu ver, faz a superioridade de Lucrécio. Enquanto Epicuro está interessado em usar sua teoria exclusivamente para "banir os deuses da natureza", tratando, assim, a ciência apenas como "uma arma contra a superstição" (p.284), em Lucrécio percebe-se o amor pela natureza, o prazer em conhecê-la. O que faz a superioridade da obra deste, o que faz com que ela não seja "fria e banal", é o fato de ele ser um "observador apaixonada da natureza". Isso o leva a perceber tanto aquilo que seduz o artista - "o lado pitoresco, as nuanças móveis e mutáveis" -, quanto o que interessa ao geômetra.

É esta aptidão de Lucrécio em captar de um só golpe o duplo aspecto das coisas que faz a incomparável originalidade de sua poesia, de sua filosofia, em uma palavra, de seu gênio. Se ele tivesse se limitado a pintar a natureza por fora, a sua descrição teria sido fria e banal. Se ele tivesse somente desenvolvido em versos latinos a teoria dos átomos, ele poderia ter sido o mais seco dos geômetras. Mas a sua descrição não é fria, porque ele não descreve, nós o sentimos bem, pelo simples prazer de descrever: como a teoria dos átomos o preocupa sem cessar, ele descreve para provar, e sobre cada uma de suas descrições passou como um sopro oratório que o anima e nos arrasta. E a sua geometria não é absolutamente seca, porque ela é viva como a natureza, porque o poeta não se representa os compostos de átomos em sua nudez fria, assim como o fazia Demócrito, mas os reveste em seguida, e malgrado ele, com as cores que a sua imaginação reconhece ou empresta à realidade (p.285).

A paixão de Lucrécio pela natureza se estende à natureza humana a respeito da qual tem uma concepção bem original. $\mathrm{O}$ atomismo em Epicuro leva ao afastamento da superstição, dos temores pueris, da vida política e familiar, das preocupações e paixões, excluindo, assim, "a 
melancolia, a tristeza, tudo o que perturba a alma", produzindo um "estado de equilíbrio" do qual "nasce uma felicidade durável (...) uma alegria tranqüila e pouco intensa, mas contínua", uma "quietude" e uma "inalterável serenidade" (p.287); daí a receita para a felicidade. Em Lucrécio, a concepção materialista determinista tem outras implicações nas quais se revela um pessimismo indisfarçável - melancolia e tristeza - em relação à condição humana, à sua impotência diante do inevitável. Lucrécio, diferentemente de Epicuro, apieda-se da condição humana.

Como a fatalidade das leis naturais é o que o tem sobretudo tocado na doutrina dos átomos, o poeta foi tomado, malgrado a serenidade que ostenta, de uma piedade dolorosa por esta humanidade que se agita sem resultado, que luta sem proveito, e que as leis inflexíveis da natureza conduzirão, malgrado ela, no imenso turbilhonamento das coisas. Por que trabalhar? fatigar-se? por que lutar, por que se lamentar? Nós sofremos a lei comum, e a natureza se preocupa pouco conosco. Que um vento carregado de germes envenenados sopre sobre a terra, uma epidemia nascerá. E é sobre a espantosa descrição da peste de Atenas que o poema termina. Lucrécio quis mostrar a impotência dos homens e dos deuses em presença das leis da natureza; ele quis que o quadro fosse assustador, que a tristeza invadisse a nossa alma, e que esta fosse a nossa última impressão. Ele foi bem sucedido; e a piedade sincera, profunda, que ele testemunha à humanidade sofredora faz com que nós nos liguemos a ele, que nós o amemos, ao mesmo tempo que ele dá à sua doutrina e a seu poema uma originalidade que tem seu preço (p.287).

Assim, a grande admiração de Bergson por Lucrécio reside naquilo que considera como o elemento original e apaixonante da obra do poeta: a solidariedade de Lucrécio em relação à situação do homem no mundo revela que ele foi capaz de perceber as implicações existenciais negativas da concepção materialista determinista, mais particularmente, a impotência do homem e a conseqüente tristeza. Os elogios de Bergson a Lucrécio sugerem sua aprovação em relação às implicações que o poeta extrai de uma concepção determinista. Diante do determinismo, o otimismo surge como impossível, ou pelo menos, artificial, fingido, não autêntico. Parece, então, ser bastante sugestivo que encontremos na obra de Bergson uma crítica incansável a todas as formas de determinismo e, ao mesmo tempo, a defesa constante da liberdade. Bergson aponta uma alternativa à concepção que traz consigo não apenas o pessimismo e a melancolia como uma conseqüência inevitável, mas, principalmente, a apatia inerente a uma visão de mundo, segundo a qual tudo está determinado e nenhum esforço vale a pena. Sua obra poderia, então, ser compre- 
endida como uma grande réplica às bases teóricas do pensamento de Lucrécio, como uma reação contra o determinismo e suas implicações negativas.

\section{5}

Parece-nos que essa interpretação bergsoniana de La nature, que privilegia as implicações de uma certa teoria da natureza, reflete a inquietação que o próprio filósofo experimentou desde cedo diante do determinismo em suas mais variadas formas. De fato, Bergson não abandonou essa perspectiva, a qual reaparece posteriormente, sempre privilegiando o mesmo enfoque negativo.

É que vemos, por exemplo, na segunda das conferências que Bergson (1972, p.982) realizou em 1913 nos Estados Unidos, portanto, trinta anos após a publicação dos Extraits de Lucrèce, onde trata tanto das origens do determinismo quanto de suas implicações. Considera que a forma inicial do determinismo foi a "antiga crença no destino"; diante dos obstáculos que o homem encontrava, o destino lhe aparecia como "uma espécie de peso que o oprimia e limitava sua liberdade de ação". Daí para a crença na "necessidade", na "inevitabilidade de todo ato", foi "somente um passo". O medo, a angústia e a tristeza aparecem associados ao determinismo, só que agora como responsáveis pela crença no destino: eles "insinuam-se como micróbios em um ser moralmente saudável", desculpando as suas falhas. Nesse sentido, o filósofo considera o fatalismo, aceito algumas vezes por vaidade, pelo fato de fazer os homens se "sentirem os agentes de um poder mais vasto do que o seu próprio", como a "apologia da inação" e do "erro". Para Bergson, é também por vaidade que muitos homens acreditam na inevitabilidade da história das nações, sentindo-se, assim, de certa forma, gratificados: "é mais agradável pensar que o curso de nossa história nacional, com seus equívocos, crimes e falhas, foi inevitável, do que pensar que nós ou que nossos irmãos poderiam tê-lo mudado para melhor" (idem, ibidem). Encontramos, assim, um mesmo elemento fundamental que estava presente em seu texto sobre Lucrécio, a tese de que o determinismo faz com que os homens se sintam impotentes, estimulando o comodismo e a apatia.

Nesse sentido, podemos ver a obra de Bergson como um imenso esforço de reação contra essa legítima - pois justifica-se a partir da estrutura da mente -, mas inconsistente - não se justifica a partir das razões 
alegadas - visão de mundo. É o que Bergson expressa claramente em um texto de 1912, no qual, respondendo a uma enquete sobre a juventude, afirma que sua obra é uma reação necessária e bem sucedida contra o determinismo generalizado e falsamente científico e contra as suas conseqüências negativas inevitáveis:

Há quase quarenta anos, os filósofos e os sábios nos diziam: o homem não é nada além de um ser submetido à influência de um certo meio, sofrendo certas forças contra as quais sua vontade é sem efeito, obrigada a se submeter sem poder resistir à hereditariedade, à educação, etc., e nós aceitamos tudo isso, quando, no fundo de cada um de nós, nossa consciência protestava e gritava: mas vá, tu és livre e responsável! Era preciso uma reação, confessemo-lo, contra essa falsa filosofia disfarçada em ciência. Certamente, ninguém mais que eu reverencia a ciência, a verdadeira, mas não a contrafação desta que se queria impor ao mundo. E me pareceu que era preciso reagir o mais cedo possível contra esta concepção tão falsa, que não tenderia nada menos que a fazer do homem um ser passivo, amorfo, sem espontaneidade, sem vontade (...), uma coisa, para dizer tudo. Esta reação, nós a temos operado, e, os senhores o vêem, ela começa a dar seus frutos (Bergson, 1972, p.969).

Contra a tristeza e a apatia inerentes ao determinismo a obra de Bergson constitui-se como uma ontologia da liberdade propiciadora de alegria e otimismo ${ }^{3}$.

Mas nós ganharemos também por nos sentir mais alegres e mais fortes. Mais alegres, porque a realidade que se inventa sob nossos olhos dará a cada um de nós, sem cessar, certas satisfações que a arte fornece de tempos a tempos aos privilegiados da fortuna; ela nos descobrirá, para além da fixidez e da monotonia que nela apercebem de início nossos sentidos hipnotizados pela constância de nossas necessidades, a novidade sem cessar renascente, a movente originalidade das coisas. Mas nós seremos sobretudo mais fortes, porque à grande obra de criação que está na origem e que prossegue sob nossos olhos nós nos sentiremos participar, criadores de nós mesmos. Nossa faculdade de agir, em se reapoderando, se intensificará. Humilhados até aí em uma atitude de obediência, escravos de não sei quais necessidades naturais, nós nos redirigiremos, mestres associados a um maior Mestre. Tal será a conclusão de nosso estudo (...) Este pode ser uma preparação para bem viver (Bergson, 1993, p.116).

\footnotetext{
3 Como sugere o ensaio Le possible et le réel, de 1930, que passou a integrar o livro La pensée et le mouvant (1993)
} 
COELHO, J. G. Bergson reader of Lucretius: the existential implications of determinism. Trans/Form/Ação, (São Paulo), v. 26, p.129-140, 2003.

n ABSTRACT: We take as object of analysis Bergson's early work, Extraits de Lucrèce, trying to show that by privileging the negative existential implications of determinism, he prefigures and justifies his having dedicated a great deal of his later philosophical thought to a criticism of determinism and a defense of liberty.

n KEY-WORDS: Bergson; Lucretius; determinism; existential.

\section{Referências Bibliográficas}

BERGSON, H. Mélanges. Paris: PUF, 1972.

. La pensée et le mouvant. Paris: PUF, 1993. 